Revista de Comunicación y Salud, 2019, Vol. 9, n² 2, pp. 27-46

Editado por Cátedra de Comunicación y Salud

ISSN: 2173-1675

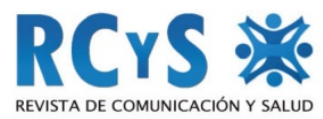

Enviado 05/12/2019

Aprobado 20/12/2019

\title{
CAMBIOS SOCIALES Y COMUNICATIVOS A TRAVÉS DE LA PUBLICIDAD MÉDICA Y FARMACÉUTICA EN LA PRENSA HISTÓRICA DE BILBAO, 1885-1936
}

\section{Social and communicative changes through medical and pharmaceutical advertising in Bilbao historical newspapers, 1885-1936}

Manuel Montero. Universidad del País Vasco. España. manuel.montero@ehu.eus

Nuria Rodríguez-Martín ${ }^{1}$. Universidad de Málaga. España. nuriarm@uma.es

Financiación. Este texto forma parte de los resultados del proyecto de investigación I+D HAR201676759-P "La definición de la sociedad de masas. Bilbao, un engranaje urbano, 1900-1936", financiado por MINECO y Fondos FEDER, y ha sido posible por la concesión de una Ayuda para la incorporación de Doctores del I Plan Propio de Investigación y Transferencia de la Universidad de Málaga.

\section{Resumen}

En las últimas décadas del siglo XIX y primeras del XX la publicidad se convirtió en una herramienta comunicativa que coadyuvó a las transformaciones sociales en el mundo urbano español. Este artículo analiza los cambios sociales y comunicativos acaecidos en la España urbana de dicho periodo, a través del análisis de los anuncios impresos del sector de la salud, publicados en las principales cabeceras de la prensa de Bilbao, incluyendo las de mayor circulación en esos momentos. El trabajo trata de establecer tanto el público al que iban destinados, como las innovaciones acaecidas en el sector a lo largo de las décadas estudiadas.

Palabras clave: publicidad, medicinas, salud, consumo, Bilbao.

\section{Abstract}

Throughout the last decades of the $19^{\text {th }}$ Century and first decades of the $20^{\text {th }}$ Century, advertising became a key communicative tool that contributed to social transformations in urban Spain. This paper studies social and communicative changes arisen in the country at that time, by analyzing a sample of medical and pharmaceutical advertisements published and collected in Bilbao's historical newspapers, included

\footnotetext{
${ }^{1}$ Autora para correspondencia: Nuria Rodríguez Martín, Universidad de Málaga, nuriarm@uma.es
} 
Cambios sociales y comunicativos a través de la publicidad médica y farmacéutica en la prensa histórica de Bilbao, 1885-1936

those of highest circulation in the city. The research intends to determinate both the audiences and the innovations that happened within the sector at that time.

Keywords: advertising, pharmaceutical \& medical products, health, consumption, Bilbao.

\section{Cómo citar el artículo}

Montero, M. y Rodríguez-Martín, N. (2019). Cambios sociales y comunicativos a través de la publicidad médica y farmacéutica en la prensa histórica de Bilbao, 1885-1936. Revista de Comunicación y Salud, 9(2), 27-46.

doi: http://doi.org/10.35669/revistadecomunicacionysalud.2019.9(2).27-46

\section{INTRODUCCIÓN}

La publicidad es uno de los fenómenos culturales más característicos de la sociedad contemporánea, una herramienta comunicativa que ha contribuido decisivamente a moldear los valores, aspiraciones, estilos de vida y arquetipos sociales a lo largo de los dos últimos siglos (Eguizábal, 2009). No obstante, los anuncios, en sus distintos soportes, siguen siendo una fuente documental poco explotada por la historiografía española, con excepciones (Marchamalo, 1996; De Andrés del Campo, 2005; Bermejo Barrios, coord., 2005; Balandrón Pazos, Correyero-Ruiz y Villalobos Montes, 2007; Rodríguez Martín, 2008; González Mesa, 2010; Montero, 2011; Rodríguez Martín, 2015).

Este artículo pretende realizar una contribución al estudio de las transformaciones socio culturales en el mundo urbano español del primer tercio del siglo $\mathrm{XX}$, a través del examen de una muestra amplia y representativa de anuncios de productos médicos y farmacéuticos, divulgados a lo largo de las últimas décadas del siglo XIX y primeras del siglo $X X$ en varias cabeceras históricas publicadas en Bilbao, incluyendo las de mayor circulación del periodo: El Noticiero Bilbaíno, El Liberal, El Nervión, El Porvenir Vasco, La Gaceta del Norte y Euzkadi. Igualmente, hemos revisado los anuncios del sector de la medicina y la farmacopea aparecidos en algunas cabeceras editadas en la segunda mitad del siglo XIX, como por ejemplo Irurac Bac, para tratar de contextualizar y explicar con mayor rigor y exactitud los cambios acaecidos en el periodo subsiguiente.

Metodológicamente, hay que señalar que el análisis se centra, por una parte, en la evolución del número de anuncios y anunciantes, así como en el tipo de productos y servicios médicos publicitados. Asimismo, se analizan los eslóganes, textos, tipografía e imágenes comerciales utilizadas en la composición de las piezas publicitarias. La investigación se fundamenta por tanto en anuncios impresos históricos, y se complementa con otras fuentes secundarias, como revistas especializadas y publicaciones médicas editas en el periodo de referencia. 
Cambios sociales y comunicativos a través de la publicidad médica y farmacéutica en la prensa histórica de Bilbao, 1885-1936

\section{LA DESPENSA MÉDICA: ORÍGENES Y EVOLUCIÓN}

Los remedios médicos formaban parte fundamental de la despensa doméstica en la sociedad urbana del primer tercio del siglo XX. Así se deduce de la publicidad relacionada con la salud que se insertaba en la prensa. Durante gran parte del periodo fue el grupo de anuncios más importante, si bien su peso relativo menguó en los años veinte, cuando se produjo un aumento considerable de la publicidad de productos de marca de los sectores de la cosmética e higiene personal, y de la alimentación. También de los nuevos productos de consumo que comenzaron a inundar el mercado en ese periodo, como los automóviles y los primeros electrodomésticos, además de comercios y establecimientos de ocio y restauración, algunos de gran modernidad, como tintorerías y tiendas de fotograbado.

Hasta ese momento, la publicidad de productos médicos y farmacéuticos diseñó los anuncios de mayor tamaño, siendo frecuente el empleo de grafismos y de un lenguaje propio, algo inusual en otros sectores. Sus grabados dibujaban dos polos, el paciente dolorido -sufriendo, descansando si ha llegado a convaleciente- y el ya curado, rebosante de salud. Sin espacios intermedios: o enfermo o pletórico. En medio quedaba la acción médica, a veces milagrosa, de creer a los anuncios. La publicidad médica retrataba situaciones extremas, la salud a borbotones y la enfermedad sin paliativos -0 antes de que éstos actuaran- pero no dos mundos sociales. Sus imágenes presentaban siempre una fisonomía burguesa: en la salud y en la enfermedad. Si el tamaño y frecuencia de las inserciones publicitarias se corresponden con el interés consumidor, en muchas despensas los remedios médicos tenían un lugar preferente. Estos anuncios desvelan las soluciones comercialmente más difundidas, aunque a veces queda la duda de su utilidad médica. La argumentación publicitaria a la que recurrían nos aproxima a la mentalidad de algunos grupos urbanos ${ }^{2}$.

Analizamos aquí la publicidad médica de la prensa bilbaína durante las décadas finales del siglo XIX y primeras del XX en El Noticiero Bilbaíno, El Liberal, El Nervión, La Gaceta del Norte y Euzkadi ${ }^{3}$. El más representativo de estos diarios fue el primero, el de mayor continuidad, lo que nos permite trazar la evolución entre 1885 y 1936 -los anuncios del siglo XIX nos sirven para interpretar los años posteriores-. El Noticiero Bilbaíno fue el periódico de referencia en Bilbao, además de la cabecera que mayor número de anuncios insertaba. A comienzos de los años veinte le igualó en inserciones

\footnotetext{
${ }^{2}$ Para el caso de Inglaterra, véase el trabajo de Barker (2009), en el que la autora analiza el boom de la publicidad médica en los diarios de Manchester, Liverpool, Leeds y Sheffield entre 1760 y 1820 , en el contexto de crecimiento urbano del periodo, y en relación a la noción de "confianza", para explicar el desarrollo de nuevos patrones de consumo.

${ }^{3}$ La obra de referencia para el estudio de la prensa española en este periodo es el completo estudio de Seone y Saiz (1996), donde pueden consultarse los datos sobre fundación, filiación, tiradas y lectores de las cabeceras en circulación en estos años, incluyendo las que sirven de base a este trabajo, a excepción de El Nervión. El decano de la prensa bilbaína es El Noticiero Bilbaíno, fundado en 1875 y en circulación hasta 1937. El Liberal, republicano independiente y La Gaceta del Norte, católico, se fundaron en 1901, y el nacionalista Euzkadi en 1913. Sobre la prensa vasca en particular, véase, Sáiz Valdivielso (2000) y Urquijo Goitia (2005).
}

Revista de Comunicación y Salud, 2019, Vol. 9, n² 2, pp. 27-46 
médicas el periódico El Liberal. En un día elegido como representativo, el 30 de junio de 1921, la publicidad médica en los periódicos bilbaínos fue la siguiente, medida en número de anuncios publicados:

Tabla 1. Número de anuncios en las cabeceras citadas, 30 de junio 1921.

\begin{tabular}{|l|c|}
\hline Cabecera & $\begin{array}{c}\mathbf{N}^{\circ} \mathbf{~ d e ~} \\
\text { anuncios }\end{array}$ \\
\hline El Noticiero Bilbaíno & 38 \\
\hline El Liberal & 37 \\
\hline Euzkadi & 17 \\
\hline El Nervión y la tarde & 10 \\
\hline Gaceta del Norte & 10 \\
\hline
\end{tabular}

Fuente: elaboración propia.

La equiparación entre El Noticiero Bilbaíno y El Liberal sólo se produjo por entonces. No cuestionó el liderazgo del primero en la publicidad de medicinas, pues la mayoría de los del segundo eran de médicos, y no de medicinas. Como veremos, el contraste remite a la segmentación social que se produjo en la publicidad. Desde los años ochenta del siglo XIX la publicidad médica tenía en la prensa bilbaína una presencia muy alta, las dos últimas décadas del siglo más del $20 \%$ de los anuncios. La elevada presencia de estos reclamos en los diarios de Bilbao se corresponde con lo que sucedía en la prensa ilustrada de difusión nacional a finales del diecinueve (Fernández Poyatos, 2011, p. 121). El mayor crecimiento lo experimentó en los años noventa, cuando superó holgadamente los 30 anuncios por número. Después se estancó, con altibajos entre 25 y 44 -la publicidad presentaba un acusado ritmo estacional, por lo que en las series continuas nos atenemos a fechas homogéneas-. Durante los años treinta del siglo XX superaba los 20 , incluso en los meses en los que esta publicidad decaía. Eso sí, esta publicidad perdió importancia relativa, pues no siguió la expansión de anuncios cuando llegaron a superar los 200 y acercarse a los 300, la mayoría anuncios por palabras.

Como hemos señalado más arriba, para este estudio tienen interés los anuncios médicos de la segunda mitad del siglo XIX, pues nos permiten interpretar con mayor precisión los cambios ocurridos en las décadas posteriores. Antes de la última guerra carlista usaban ya un lenguaje publicitario propio, no exento de cierta agresividad. Eran los más extensos, con prolijas explicaciones sobre enfermedades, premios recibidos y virtudes del medicamento. Predominaban los productos-milagro, que se presentaban como solución para curar una amplia gama de padecimientos. El Rob BoyveauLafecteur, por ejemplo, se publicitaba en 1868 como remedio para curar "radicalmente las enfermedades cutáneas, los empeines, los abcesos [sic] los cánceres, las úlceras, la sarna degenerada, las escrófulas, el escorbuto, pérdidas, etc." ${ }^{4}$ Las Píldoras y

${ }^{4}$ Anuncio Rob Boyveau-Lafecteur, (1868, mayo 23) Irurac bat. 
Cambios sociales y comunicativos a través de la publicidad médica y farmacéutica en la prensa histórica de Bilbao, 1885-1936

Ungüento Holloway, por su parte, terminaban, según explicaban en sus anuncios, con "la impureza de la sangre", origen de todas las enfermedades; Sabemos que no tenían principio activo ninguno, excepto el efecto placebo, pero se le atribuían todo tipo de virtudes: "espulsa [sic] toda partícula morbosa, refrigera y limpia todas las partes enfermas" 5 .

Las técnicas publicitarias basadas en un lenguaje técnico, anuncios de gran formato, mención de premios y eficacia contra una amplia gama de enfermedades, las encontramos en los años posteriores a la tercera guerra carlista. Tenían nombres sugerentes, contenido incierto y usaban recurrentemente el calificativo "depurativo". Sugerían que la panacea en cuestión depuraba el cuerpo e impedía la aparición de enfermedades o las curaba ${ }^{6}$. Así, el Jarabe de zarza de Honduras yodurado de Orive, "depurante, antiescrofuloso y antisifilítico", curaba lo mayor y lo menor. O lo prevenía, publicitándose su aplicación para la curación de los efectos de la sífilis y de "los infartos recientes y crónicos, en las erupciones cutáneas, en las caries de los huesos, y en fin, combate eficazmente todo vicio de la sangre que suele manifestarse por turbaciones en el oído y vista y pesadez del cuerpo". Utilizaba una publicidad comparativa, citando a sus competidores, afirmando que superaba a otros depurativos como el Rob Lafecteur Rob Claret, "envueltos en la farsa del secretismo"7. A partir de 1880 los anuncios médicos crecieron espectacularmente en nuestra muestra, desde los 7 diarios a los 38 en 1900. El principal crecimiento se produjo en los años noventa, coincidiendo con el asentamiento de las clases medias bilbaínas. El interés por los remedios médicos quedó asociado a este ámbito. Buena parte de los anuncios médicos eran de productos extranjeros -era el único sector en el que ocurría esto- y reproducían argumentaciones y grafismos usados en Estados Unidos, Gran Bretaña o Francia. Su modernización publicitaria introducía criterios internacionales.

En los últimos veinte años del siglo XIX, podemos destacar una serie de características. En primer lugar, el mantenimiento de depurativos y reconstituyentes como productos de obligada presencia en los botiquines. Se constata además que dejaron de ser de composición innominada, recogiendo los anuncios información sobre el producto en el que se basaba: ferruginosos, fosfatados, vinos quinados, vinos de kola, magnesio, concentrados de carne o harinas... La mayoría de ellos se presentaban como la panacea capaz de combatirlo todo, explotando la idea de que las enfermedades aparecían por impurezas en la sangre. Así, el Hierro Bravais combatía la anemia, la clorosis, la debilidad, la extenuación..., el Vino de Bellini con quina y Columbo, el empobrecimiento de la sangre, colores pálidos, calenturas, fiebres ${ }^{8} . .$. En

${ }^{5}$ El Ungüento Holloaway decía ser un «curativo infalible para la escrófula, los cánceres, los tumores, los males de piernas, la rigidez de las articulaciones, el reumatismo, la gota, la neuralgia, el tic-doloroso y la parálisis». Anuncio Píldoras y Ungüento Holloway, (1868, marzo 25) Irurac bat.

6 El Jarabe Depurativo Ricord Favrot, por ejemplo, afirmaba ser indispensable para «curar completamente las enfermedades del cutis y para acabar de purificar la sangre después de un tratamiento anti-sifilítico». Como preventivo, decía servir para evitar «todos los accidentes que pueden resultar de la sífilis constitucional». Anuncio Ricord Favrot, (1876, agosto 3) El Noticiero Bilbaíno.

${ }^{7}$ Anuncio Jarabe de zarza de Honduras yodurado de Orive, (1876, agosto 3) El Noticiero Bilbaíno.

${ }^{8}$ Anuncio Vino de Bellini, (1880, junio 12) El Noticiero Bilbaíno. 
Cambios sociales y comunicativos a través de la publicidad médica y farmacéutica en la prensa histórica de Bilbao, 1885-1936

la misma línea, a los purgantes se les atribuía también una eficacia extraordinaria ${ }^{9}$. Aparecieron genéricos que no lo curaban todo, pero sí un determinado tipo de enfermedades, por ejemplo, las de los nervios, como el Jarabe al Bromuro de Potasio de cortezas de naranjas amargas, contra "la epilepsia, la histeria, la migraña, el baile San Vito, insomnios, convulsiones [...] en una palabra, todas las afecciones nerviosas"10. Igualmente, se advierte una tendencia a la especialización -como garantía de eficacia, reclamo publicitario o por ambas razones- que se confirma también en la aparición de específicos. El Jarabe y Pasta Pectoral de P. Lamouroux curaba las "Enfermedades del pecho"11, los Polvos y Pastillas Paterson, las del estómago ${ }^{12}$. Y había cápsulas contra enfermedades contagiosas ${ }^{13}$, pomadas para los ojos, algunos productos dentífricos (en polvo y en pasta).... Los más anunciados combatían las enfermedades venéreas. Eran las cápsulas de Raquin, la Injectio Brouy o las inyecciones Ricord Favort.

Una tercera característica es la inclusión como reclamos para la salud de las aguas minero-medicinales, particularmente cuando se produjo la epidemia de cólera, también combatida por algunos licores -anís-, vinos y algún dentífrico. Dichas aguas se presentaban como panaceas. Así por ejemplo, el Agua de Loeches La Margarita afirmaba curar "escrófulas, herpes, reumatismo, sífilis, úlceras, infartos de la matriz, flujo blanco, dolor de estómago...", además de ser "el purgante más barato, suave y eficaz" ${ }^{14}$. También fueron apareciendo productos relacionados con el sector de la higiene y belleza, como tintes para el cabello, cremas para el cutis, remedios contra la calvicie, depilatorios, polvos cosméticos o píldoras para el desarrollo del pecho femenino. La modernidad quedaba así asociada al cuidado corporal y a la belleza. Además, y de forma creciente, estos anuncios incluían los de médicos. La ciudad crecía y no bastaban ya los conocimientos personales o los círculos de conocidos, era necesaria la publicidad. Los médicos se publicitaban como especialistas -dentistas, callistas, enfermedades nerviosas, respiratorias, "garganta, nariz y oído" ${ }^{15}$, etc.-. Tenían también un gran peso los de "piel, sífilis, secretas y venéreas".

Algunos cambios de los últimos años del siglo apuntan a la modernización de la publicidad médica. Crecía la especialización y adquirían fuerza los productos contra la tos, el catarro y los resfriados. Las marcas comerciales iban adquiriendo un claro protagonismo, avaladas por un fabricante. Era frecuente que aseguraban que servían

${ }^{9}$ Las Píldoras Sanativas del Dr. Jayne, por ejemplo, se ofrecían como «un purgante seguro», que combatía el estreñimiento, pero también ofrecían restablecer «la acción del hígado removiendo las obstrucciones del ducto biliario», así como cambiar «gradualmente las secreciones viciadas del estómago y del hígado». Anuncio Pildoras Sanativas del Dr. Jayne, (1880, junio 16) El Noticiero Bilbaíno.

${ }_{10}$ Anuncio Jarabe al Bromuro, (1882, diciembre 23) El Noticiero Bilbaíno.

11 «Tos, gripe, Tos ferina, Bronquitis, Catarro». Anuncio Jarabe Pectoral de P. Lamouroux, (1880, marzo 9) El Noticiero Bilbaíno.

12 «Estos polvos y estas pastillas antiácidas y digestivas curan los males de estómago, falta de apetito, digestiones laboriosas ó difíciles, acideces, vómitos, náuseas, cólicos», rezaba su anuncio publicado en (1878, mayo 22) El Noticiero Bilbaíno.

${ }^{13}$ Como las Capsules Mothes, (1880, junio 12) El Noticiero Bilbaíno.

${ }_{14}$ Anuncio Agua de Loeches La Margarita, (1880, diciembre 24) El Noticiero Bilbaíno.

${ }^{15}$ Anuncio Consultorio Médico, (1899, agosto 22) El Porvenir Vasco. 
para todas las enfermedades respiratorias. En 1900 hemos localizamos más de 20 marcas entre cigarrillos, polvos, caramelos, pastillas, inhaladores, jarabes, emplastes.... Proliferaban además los productos para toda clase de padecimientos físicos: contra las lombrices, pomadas contra las almorranas, callicidas, elixires estomacales, "granos de salud contra el estreñimiento", linimentos, elixires contra insomnios, cápsulas de sándalo contra las enfermedades urinarias. etc. Se imponían la atención específica a cada dolencia y las medicinas con finalidad bien definida. Hacia 1900 aparecían también productos con respaldo científico, tales como vacunas, bicarbonato de sosa, agua oxigenada o analgésicos.

\section{LA DESPENSA MÉDICA: LA MODERNIZACIÓN}

Si los anuncios de prensa dedicados a la salud constituyen un indicio de las medicinas que había en la despensa doméstica, ésta comenzó a vaciarse a fines de los años veinte. Desde 1930 la modernización redujo las ofertas mercantiles de medicinas y aumentó la presencia de especialistas. Nos encontramos por tanto con una racionalización en los tratamientos sanitarios. Los remedios que llegaban a la publicidad tenían características nítidas: dedicados a la belleza y depurativos o específicos de marcas bien asentadas. Se había impuesto la desconfianza ante los productos milagrosos, al tiempo que, aparentemente, se otorgaba un mayor papel al médico en la gestión de la salud. Los anuncios médicos habían llegado a su máximo hacia 1915.

En el primer tercio del siglo XX proliferaban los anuncios médicos, pero la modernización se notaba en diversos cambios, iniciados en los años noventa: específicos, reformulación de los depurativos y/o reconstituyentes y consolidación de productos asociados a la belleza. Además, desaparecieron las medicinas para venéreas, que en el nuevo siglo sólo ocasionalmente llegaban a los anuncios. No fue por la menor presencia de estas enfermedades, sino por nuevos tratamientos, que no podían venderse al modo del mercado libre que sugieren los anuncios, pues requerían el control médico.

Los "depurativos" no eran ya las panaceas de contenido incierto del siglo XIX, y hasta 1920 resultaban obligados en cualquier despensa que reprodujese los anuncios. Las piezas publicitarias consultadas solían mencionar la composición, que así formaba parte del reclamo, como sugerencia de eficacia: jugo de carne de buey, yoduro de hierro, clorhídrico fosfato de cal, fosfatado, ferruginoso, fosfatina, creosota, concentrado de harinas, caldo de cereales, gofio canario, compuesto de vegetales... ${ }^{16}$. Eran principios activos avalados científicamente, al margen de que sugirieran unos efectos amplísimos, no siempre verosímiles.

Si faltaba la composición, la argumentación estaba muy desarrollada. El Jarabe Pagliano era "verdadero depurativo y refrescante de la sangre, de fama mundial,

\footnotetext{
${ }^{16}$ Así se anunciaba el Rob Xarrié, "depurativo de la sangre" y que «cura radicalmente herpes, escrófula y demás afecciones de la piel», efectos amplios y diversos que contrastan con la precariedad del anuncio en cuanto a su composición vegetal.
}

Revista de Comunicación y Salud, 2019, Vol. 9, n² 2, pp. 27-46 
Cambios sociales y comunicativos a través de la publicidad médica y farmacéutica en la prensa histórica de Bilbao, 1885-1936

premiado con las más altas honorificiencias [sic]". Se advertía contra falsificaciones ciertas o no, constituía un recurso publicitario-. Concluía: "el jarabe Pagliano es necesario en todas las familias" ${ }^{17}$. Algo parecido sucedía con el Purgante Yer -su composición química, que conocemos, no resultaba sugerente publicitariamente- y el Phoscao, si bien el nombre sugería la combinación entre fosfatos y cacao.

La mención de su composición quitaba empaque milagroso, pero eso no era óbice para que la publicidad asegurara su capacidad de curar una amplísima gama de enfermedades. El vino de kola de Pinedo -un farmacéutico bilbaíno- era un "tónico nutritivo", compuesto de kola, coca, cacao y guarano, y combatía clorosis, anemia, raquitismo, enfermedades nerviosas, cardiacas y genéricas. También los Glicerofosfatos Botta\&Baltá combatían "el raquitismo, falta de desarrollo orgánico, clorosis, anemia y colores pálidos"18. Tal argumentario se sustentaba en la idea, heredada del siglo anterior, de que la "pobreza de sangre" era la antesala de la enfermedad. Si se eliminaba, terminaba la debilidad, evitando "una vejez prematura y anemia cerebral". Daba igual que fuese ioduro de hierro o clorhídrico fosfato de cal; La composición química asemejaba a los depurativos con los productos milagrosos del siglo anterior: la modernidad estaba en los nombres de resonancia científica, no en la limitación de sus efectos. Publicitariamente hablando.

Según la literatura médica de la época, tales productos tenían principios activos que actuaban positivamente sobre la salud, bien que no con la eficacia que se deducía de la publicidad. Por ejemplo, el fosfato de cal administrado a los niños en estado puro servía de base en los tratamientos antirraquíticos y antidiarréicos ${ }^{19}$. Según el anuncio de la Solución Cases era "el más poderoso de los reconstituyentes para los casos de debilidad general, clorosis, raquitismo, tisis, falta de apetito" 20 . Se comercializaban de forma masiva productos antes elaborados en pequeñas dosis por farmacéuticos. "EI ioduro de hierro unido á una sustancia nutritiva y corroborante puede producir curaciones aun en los casos de aniquilamiento más graves" (De Bruc, 1873, p. 187). A veces se intuye que la sensación de eficacia tenía otro origen. En 1925 se vendía el Elixir Vitoserum Oliver Rodés, para los estados de debilidad general, neurastenia, fatiga mental y anemia. No decía la composición, pero sabemos que llevaba glicerofosfato sódico, eficaz suplemento en nutrición. También incluía estovaína, analgésico usado en sustitución de la cocaína, así como cacodilato de estricnina, elaborado a partir de un alcaloide. Resulta verosímil que sus efectos euforizantes acentuasen la sensación de

\footnotetext{
${ }^{17}$ El nombre con que se comercializaba aludía a las falsificaciones "Verdadero Jarabe Pagliano”, y “ $i$ «in tal marca es menester rechazarlo porque es una dañosa imitación”. Anuncio Jarabe Plagiano, (1910, diciembre 24) El Noticiero Bilbaíno.

${ }^{18}$ Anuncio Glicerofosfatos Botta\&Baltá, (1900, septiembre 16) El Noticiero Bilbaíno.

19 "Siempre que el sugeto [sic] esté flaco y debilitado, convendrá este medicamento". El Pabellón Médico, 1871 , p. 367.

${ }^{20}$ De elaboración nacional, se aseguraba que sustituía con ventaja a la Solución de Coirre, que había sido premiadas en varias exposiciones y que era «la única aprobada y recomendada por la Real Academia de Medicina y demás corporaciones médicas». Anuncio Solución Cases, (1905, febrero 24) El Noticiero Bilbaíno.
} 
Cambios sociales y comunicativos a través de la publicidad médica y farmacéutica en la prensa histórica de Bilbao, 1885-1936

eficacia del reconstituyente. Algunos anuncios avisaban de que tal depurativo no contenía opio ni opiáceos y quizás señalaba la excepción.

Si el producto era de fabricación nacional, el anuncio estaba confeccionado de forma que esto no aminorase sus virtudes. De hecho, tendía a acentuarlas, como sucedía con la Solución Cases. El Vino de Peptona Ortega -trasunto del Vino de Peptona Catillonlas tenía en grado sumo: era el mejor tónico y nutritivo para convalecientes y personas débiles, y combatía la inapetencia, las malas digestiones, la anemia, la tisis, el raquitismo, etc. El Yoduro de hierro fosfatado Elosegui fortificaba los temperamentos linfáticos, era anti-neurasténico, reconstituía el sistema óseo-muscular y reparaba los glóbulos sanguíneos. "Cura rápidamente el linfatismo, clorosis, anemia, inapetencia, clores pálidos, menstruaciones difíciles y debilidad general". La contundencia contra un amplio espectro de males no restaba credibilidad, sino que la acentuaba.

Los depurativos de grandes efectos fueron escaseando, pero en los años veinte todavía se anunciaba la Solución Pautauberge, con el esquema descrito: composición química incuestionable, "creosota y clorhidrofosfato de cal", y resultados muy por encima de lo que la experimentación médica aseguraba. De suplemento nutricional se convertía en "remedio soberano contra los catarros, las bronquitis crónicas, la gripe, el raquitismo y la escrófula". También se vendía el Purgante Yer, la hemoglobina Deschiens, la Fosfatina Falières, etc. Por contra, sólo ocasionalmente aparecen en la publicidad de los años treinta, cuando los reconstituyentes se ceñían, en nuestra muestra, al Caldo de vegetales Vigor del Dr. Falp, San Roque Jerez, Vino Ona y Phoscao. Los grupos urbanos abandonaban las panaceas de grandes promesas. Pudo contribuir el mayor rigor del Registro Farmacéutico de 1919 (González Bueno et al., 1995; Suñé Arbussa y Valverde López, 1985).

A juzgar por su continuidad publicitaria, en las dos primeras décadas del $X X$ algunos depurativos o reconstituyentes eran de presencia obligada en los botiquines. Destacaban las Píldoras y Jarabe de Blancard -con prestigio desde el XIX, compuestos por yoduro de hierro, se sigue utilizando contra la anemia -, la Solución Pautauberge, el Jarabe Pagliano, el Vino Aroud -con hierro y quina, el Jarabe de Hemoglobina Deschienes, Fosfatina Falières -un suplemento alimenticio para los niños-, píldoras Brandeth -de gran éxito norteamericano, tenía una composición estrictamente vegetal, "siempre eficaces curan el estreñimiento crónico"... y diversos padecimientos digestivos, además de purificar la sangre- y Ambrina, anunciado para los artríticos, combatía una amplia gama de dolencias, según especificaba: "sabañones, quemaduras, úlceras varicosas, reumatismo, gota..."21.

\footnotetext{
${ }^{21}$ Anuncio Ambrina, El Noticiero Bilbaíno, 1918. Sus argumentos publicitarios hacían referencia a que era un "producto nuevo", se empleaba "con gran éxito", trataba diversidad de dolencias y lo utilizaban diversas instancias extranjeras, las tres primeras de importancia en plena Guerra Europea: "Empleado por la Sanidad Militar Francesa, Almirantazgo inglés, Marina Italiana...".
}

Revista de Comunicación y Salud, 2019, Vol. 9, n² 2, pp. 27-46 


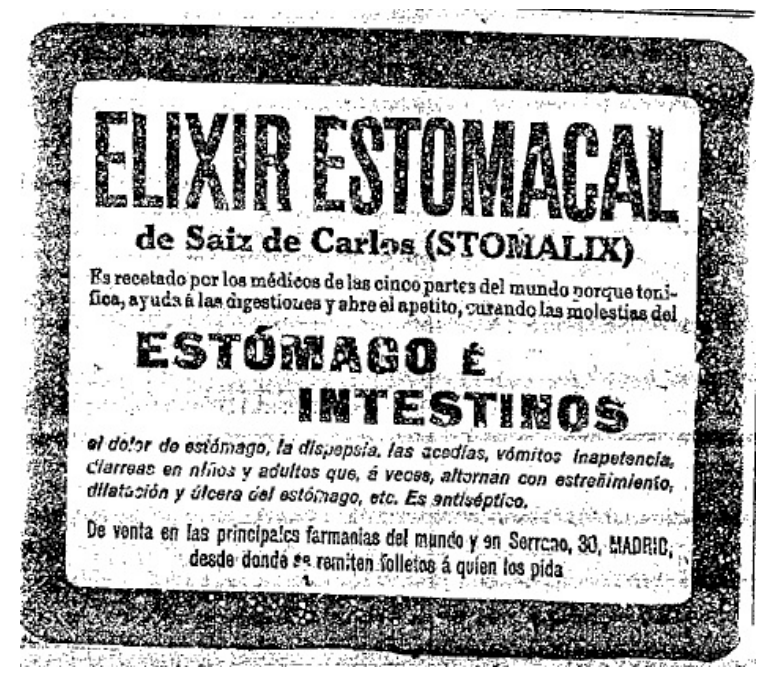

Figura 1. Anuncio del Elixir Estomacal de Saiz de Carlos. Fuente: (1922, mayo 1) El Nervión y la tarde.

La principal novedad del primer tercio del siglo XX fue la proliferación de específicos. Fueron decenas y sólo algunas marcas sobrevivieron varios años: el Elixir estomacal de Saiz de Carlos, la Cefalina del Dr. Artaza, el Jarabe Henri Mure, los Cigarrillos Espic y el Laxante Sanix, entre ellos. Quizás algunas marcas dejaron de venderse por sus efectos secundarios. A veces se anunciaron muchos productos dedicados a una misma enfermedad, quizás por aumento ocasional de la competencia, para desaparecer después. En la primera década del XX irrumpieron los productos relacionados con las enfermedades respiratorias. La mayoría se vendía para la tos y algunos para varios padecimientos. El Jarabe fenicado de Vial, tenía "eficacia segura en tos, resfriado, catarro, bronquitis, gripe, ronquera". Más habituales eran las pastillas que se ofrecían sólo para la tos, y alguna para el aliento, como las pastillas "cloro-potásicas con comino y mentol del Pinedo", fabricadas en Bilbao por la farmacia del mismo nombre, cuyos anuncios sustituían en 1905 el comino por la cocaína.

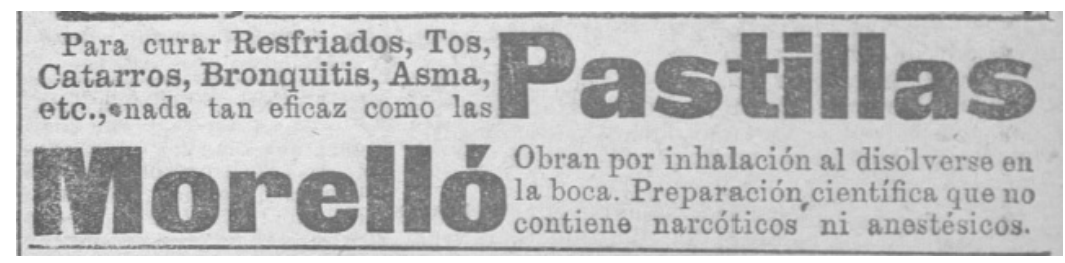

Figura 2. Anuncio Pastillas Morelló para las enfermedades respiratorias.

Fuente: (1911, enero 24) El Noticiero Bilbaíno.

Otra novedad que llegó con el siglo: los específicos relacionados con las enfermedades nerviosas. La Cefalina del Dr. Artaza se presentaba como "el más eficaz e inofensivo de los analgésicos conocidos" y se convirtió en habitual en las páginas de los periódicos. Lo mismo sucedió con el Jarabe Henry Mure. Sus anuncios no especificaban su composición, pero llevaba bromuro de calcio, relajante utilizado por

Revista de Comunicación y Salud, 2019, Vol. 9, n² 2, pp. 27-46 
Cambios sociales y comunicativos a través de la publicidad médica y farmacéutica en la prensa histórica de Bilbao, 1885-1936

entonces en este tipo de enfermedades. Si nos atenemos a los textos con los que se publicitaba $^{22}$ era un curalotodo del aparato nervioso, pues ofrecía la "curación cierta" de epilepsia, convulsiones, vértigos, desvanecimientos, etc. Aparecían además el Elixir Yvon (epilepsia, insomnio, enfermedades nerviosas) y el Nervioalmon, contra la neurastenia, que se presentaba como un depurativo que atendía a muy diversas dolencias $^{23}$. Este producto tuvo éxito, pues aparece en la publicidad en 1905 y hemos podido comprobar que aún se comercializaba en 1945. Encontramos también otros específicos.

En 1905 se anunciaba Kisley Wosmahe, un producto que combatía la "debilidad genital del hombre" y la "esterilidad de la mujer", aunque no explicaba cómo atendía objetivos tan distintos. El eventual comprador entendería bien a qué se refería, pues el anuncio se detenía en la debilidad sexual "ocasionada por la lucha de la vida, pesares, abusos de Venus o de vicios solitarios, estudios excesivos, etc." ${ }^{24}$. Se presentaba como una especie de cura natural, pero, o no fue eficaz o tuvo efectos secundarios indeseados, pues desapareció enseguida de la publicidad española. O puede ser que el relato no agradara al lector bilbaíno.

Las enfermedades digestivas tuvieron su propio tratamiento. Publicitariamente, el más importante fue el Elixir estomacal de Saiz de Carlos, la medicina española mejor considerada, que tuvo una enorme aceptación en la época. Este elixir era una creación del farmacéutico del mismo nombre, que llegó a ser diputado en Cortes. Su excelente apoyo publicitario ${ }^{25}$ transmitía la aceptación, con afirmaciones como: "apenas habrá médico que no haya recetado en la mayor parte de sus enfermedades el elixir estomacal de Sáiz de Carlos", acompañadas a veces de un grafismo moderno; El más popular representaba a un anciano que comía satisfecho. Aunque no tuvo el mismo éxito, tiene igualmente interés la Solución Estomacal Sánchez, con anuncios de gran formato en 1910. La creó un farmacéutico almeriense y la anunciaba como "el último adelanto de la ciencia médica. La renovación del estómago" ${ }^{26}$. Hubo más medicamentos de la especialidad, como el Fénix Estomacal o el Digestónico del Dr. Vicente, también anunciado como una panacea.

El reuma fue pronto objeto de específicos, pues en 1900 se anunciaba el Licor del Dr. Laville, de gran éxito en Francia, pero fue hacia 1915 cuando proliferaron las

${ }^{22}$ Epilepsia-histérico, histero, epilepsia, baile de San Víctor, enfermedades del cerebro y de la médula espinal, diabetis azucaradas, convulsiones, vértigos, crisis nerviosas, jaquecas, desvanecimientos, congestiones cerebrales, espermatorrea. Además de su eficacia incluso con enfermedades no necesariamente relacionadas con los nervios, los argumentos publicitarios mencionaban los años de "buen éxito demostrado de experiencia de los Hospitales de París" y la existencia de falsificaciones.

23 "Nerviosos. Así no es posible la vida. La neurastenia puede curarse... con el NERVIONALMON, por añeja que sea la enfermedad". La descripción se asemejaba a la de un depurativo, si bien no se citaba el enriquecimiento de la sangre: "Despierta el apetito, facilita el sueño y la digestión y regulariza el vientre".

${ }^{24}$ Impotencia. Anuncio, El Noticiero Bilbaíno, 1905.

${ }^{25}$ Saiz de Carlos destaca como una de las marcas más publicitadas en España durante el primer tercio del siglo XX, con grandes anuncios realizados por importantes agencias de la época, como la Agencia Prado, distribuidos en los principales diarios y revistas ilustradas de difusión nacional.

${ }^{26}$ Anuncio Solución Estomacal Sánchez, (1910, mayo 23) El Noticiero Bilbaíno. 
Cambios sociales y comunicativos a través de la publicidad médica y farmacéutica en la prensa histórica de Bilbao, 1885-1936

medicinas que lo trataban. Aseguraban los anuncios que atacaban el exceso de ácido úrico y ofrecían curaciones drásticas. Estaban el Urticure, para el "Baldado por dolores en las articulaciones" 27 y el Gotol, que además del reumatismo aliviaba neuralgias, jaquecas y cefaleas. Su publicidad duró poco. Más éxito tuvo el Anti-úrico Weis, de origen alemán, el primero que se autorizó en España cuando se estableció el registro. Se presentaba como "inofensivo, científico, eficaz y radical tratamiento". Incluyó la anotación, frecuente, de que no era dañino. Y la gama que afrontaba este medicamento era amplia, bien que de la misma familia: "no sólo alivia sino cura rápidamente reuma, gota, cólicos nefríticos, ciática y cálculos".

Algunos específicos se dirigían a los niños, en particular a la alimentación. Con virtudes terapéuticas o sin ellas, ofrecían suplementos alimenticios. Hubo antes anuncios aislados de este tipo, pero a partir de 1915 los encontramos de forma habitual. Destacaba el Glaxo, publicitado como "la nodriza del siglo XX", que ofrecía leche artificial procedente de leche de vaca. La publicidad de este tipo de alimentación se incrementó a partir de la década de 1920, y su comercialización llegó a un público más grande, siendo Glaxo la primera marca farmacéutica que logró un gran éxito (VV.AA., 2013, 109).

Por entonces, llegaba el Rakul, "único y verdadero alimento para niños", de presencia efímera, y la Harina lacteada Nestlé, "alimento completo para niños" ${ }^{28}$. También la Lactofitina, anunciada con el texto: "Preguntad a estos niños a qué deben salud y hermosura y os contestarán: LACTOFITINA", que se acompañaba de un grafismo que nuestra a siete niños de abundante cabellera y aspecto que hoy entenderíamos como envarado y enfermizo, pero que debía de representar la lozanía infantil en el imaginario burgués, pues la indumentaria no dejaba dudas sobre el estrato social representado.

Había también específicos para mujeres. Más abundantes durante los años veinte, los encontramos ya en los anuncios de 1900, entre los que figuraba la Apiolina Chapoteaut, que reproducía por entonces el anuncio francés, tanto en el grafismo como en el mensaje, según el cual "regulariza el flujo mensual". Las irrigaciones del doctor Valley y las de Ruiz Zorrilla curaban veinte años después las enfermedades de la matriz. Hubo muchos específicos para varias enfermedades, que aparecen ocasionalmente en nuestra muestra: callicidas -Callívoro Marthaud, el Laurel del Callicida-, antidiabéticos -El Rishi, infalible y vegetal-, laxantes -Jarabe de higos Somonte, Sanix-, contra la meningitis -Meningitina del Doctor Fulgencio de Jorge- y, a partir de 1920, medicamentos contra la sarna, entre ellos el Antisárnico Martí _"sus imitaciones resultan caras, peligrosas y apestan a letrina"- y el Sulfureto Caballero. Mención aparte merecen los remedios contra las venéreas. A fines del XIX sus

\footnotetext{
${ }^{27}$ En el ejemplo publicitario, tras varios años de sufrimiento la ingesta de Urticure había acabado con los problemas. Hacía desaparecer «la causa del reumatismo, la ciática y arenillas».

${ }^{28}$ El fabricante Nestlé y todos sus productos y marcas tuvieron una presencia publicitaria destacada en la prensa impresa en España desde finales del siglo XIX. Véase a este respecto, la obra conmemorativa editada por la actual multinacional de la alimentación (VV.AA., 1992).
}

Revista de Comunicación y Salud, 2019, Vol. 9, n² 2, pp. 27-46 
anuncios eran habituales, pero con la llegada del nuevo siglo casi desaparecieron. Ocasionalmente encontramos algún producto -Las cápsulas Koch- que "curan en dos días los flujos blenorrágico secretos recientes y modifican los crónicos", pero con los nuevos tratamientos la automedicación en enfermedades desaparecía.

Los artículos de belleza, presentados como medicamentos, tenían su propia impronta. Los encontramos ya en 1900, en la oferta de Pomada de Orive, por ejemplo, publicitada para las grietas de los pechos. Estos productos tuvieron continuidad, no obstante, su presencia fue escasa si se compara el peso de estos anuncios en los periódicos bilbaínos con el que tenían en las revistas ilustradas. Un ejemplo: un día de fines de mayo de 1905 El Noticiario Bilbaíno publicaba tres anuncios de dos productos, ambos relacionados con la calvicie -la Pomada prodigiosa del señor Vega y el Céfiro de Oriente-Lillo-. En el semanario Blanco y Negro se anunciaban ocho marcas. Dos tenían relación con el cabello, el Agua de Sales -"¡No más cabellos blancos!"- y Royal Windsor, "el célebre restaurador de cabello", que evitaba la caída del pelo, devolvía a las canas su color natural y evitaba la caspa, anunciado por el grafismo de una mujer una abundantísima cabellera. Estaba el "Parfum à la mode" Le Trefle, la Krema Kalodermina, publicitada como "insuperable para conservar la hermosura de la piel", el Dentrifique Glycerine, la Crème Simon, que servía para la "toilette diaria", y la Esencia Karistèle, de la que el anuncio reproducía el envase y se ahorraba señalar en qué consistía. La belleza venía de Francia y, al margen de los artículos dedicados a los cabellos, quedaba asociada al cuidado de la piel y a los perfumes. Estos anuncios se dirigían preferentemente al público femenino.

No era el caso de los productos relacionados con la belleza que publicaba la prensa local. La Pomada prodigiosa de Vega se anunciaba con un lema clásico -"No más calvos"- y una explicación con aire científico. El específico en cuestión destruía "la atrofia del folículo y bulbo piloso", con lo que cabello y barba crecían. El Céfiro de Oriente Lillo no decía cómo actuaba, pero sí que hacía "renacer y crecer el cabello, barba, bigote y cejas", evitando las canas y curando todas las enfermedades del cuero cabelludo. Sus eslóganes eran básicos: "i¡Murió la calvicie!!" o "El que es calvo es porque quiere". Y se empleaban otros recursos publicitarios, como el respaldo de "infinidad de eminencias médicas" y el uso por "millones de personas". Igualmente, un premio si encontraban un producto mejor.

En los diarios los problemas relacionados con los cabellos fueron los que generaron más anuncios. El Agua Flor de Oro, "que limpia y tonifica el cabello", estimulaba el funcionamiento de los vasos capilares y curaba enfermedades. Su argumentario publicitario no era sofisticado: "la desidia es casi siempre la causa de que haya tantas cabezas o con calvas o con placas o con caspa". La Loción Boyra producía similares efectos y la Tintura Mora teñía las canas; su anuncio, publicado en los años de la guerra europea, la evocaba en una peculiar versificación: "No daña ni ensucia. Con la paz, tan deseada, vendrá la fiebre inventora; mas no se inventará nada como la Tintura MORA". 
Desde finales de los años diez volvían a la prensa local los artículos femeninos. Tuvo continuidad el Agua Oriental, para obtener "en poco tiempo un pecho hermoso bien desarrollado y duro de más belleza seductora, que constituyen el mejor encanto de la mujer". Y llegaban las ansias depilatorias, a veces con reclamos categóricos: "Velludas, el Depilatorio Vasconcel de París" es "el único remedio eficaz y práctico", que conseguía debilitar la salida del vello o pelo "hasta acabar por no producirse" ${ }^{29}$. Pasada ya la confianza en los remedios drásticos, se imponía como propuesta la mejor higiene. En 1920 el Coallar Saponine Le Beuf fortificaba el cabello, saneaba la boca y reforzaba las encías. Unos años después llegaba Floroliva, que valía para "ropas finas, tocador y baño"; y el Jabón de tocador Richelet no solo hacía desaparecer "toda rojez y rugosidad", también aseguraba "el bienestar y el descanso, representa el máximum de limpieza, y es al mismo tiempo una cura de belleza", en uno anuncio de 1928, que presentaba además una sofisticada presentación gráfica, con la representación de una pareja en actitud romántica envueltos en un corazón en cuya base aparecía un dibujo del producto ${ }^{30}$. Los mensajes publicitarios de estos artículos, como vemos, se situaban frecuentemente a medio camino entre la promoción de la estética y de la salud, situándolos así en una categoría intermedia entre los sectores de la farmacopea y de la belleza y el aseo personal.

En los años veinte disminuyó el número de anuncios dedicados a la salud, no así el de médicos. En 1915 aparecieron especialistas en digestivo y Profesoras de partos, después siempre con varias ofertas, y especialistas en el aparato digestivo. Ocasionalmente también encontramos anuncios para "Herniados" y de callistas. En 1930 contabilizamos 18 anuncios de este tipo, cuando previamente sólo una vez llegó a 13. Los médicos se anunciaban explicando su especialidad. Cabe agruparlos en ginecólogos, "Garganta, nariz, oídos", respiratorio, dentistas, niños y venéreas. Tuvieron continuidad y más presencia con los años los especialistas en venéreas. Durante años se repitió un anuncio. El de 1918 decía así: "Médico especialista Venéreo y sífilis. Con cuarenta y seis años de práctica. Don Francisco López, médico ayudante mayor que fue del Hospital de especialidades de Madrid" ${ }^{31}$. Fue actualizando los años de experiencia y cambió el nombre del Hospital, que hasta 1905 era Hospital de Sifilíticos de Madrid; quizás buscaba dulcificar la expresión. También tuvieron continuidad el del Doctor Bustinza y el del Doctor Salaverri. Desde 1920 se publicitaban los nuevos tratamientos antisifilíticos. Los aplicaba la Clínica Ribera y anunciaba Salvarsan (606) y Neosalvarsan (914), nombres y números bien conocidos en la época. El Salvarsan o arsénico que salva, se había obtenido en 1910 (Fresquet Febrer, 2011).

Hubo otra novedad, la aparición de anuncios de clínicas y gabinetes médicos. El Gabinete médico del doctor Goti trataba enfermedades nerviosas, estómago y venéreas. El Gabinete Médico de Electricidad se dedicaba a la depilación, pero también a la impotencia, anemia, neuralgias, epilepsia, neurastenia "y los males del cerebro,

\footnotetext{
${ }^{29}$ Anuncio Depilatorio Vasconcel, (1919, mayo 26) El Liberal.

${ }^{30}$ Anuncio Jabón Richelet, (1928, septiembre 11) El Liberal.

31 Así mismo, ofrecía "Curaciones rápidas: tiña, herpes, flujos de oídos, úlceras de ojos, rijas, ojos torcidos, enfermedades de la matriz y partos. Hace todas clases de curaciones. Asiste a las casas".
}

Revista de Comunicación y Salud, 2019, Vol. 9, n² 2, pp. 27-46 
garganta, pecho, matriz y recto". La Clínica Dental, el Instituto Dental y la Policlínica Moderna reflejaban esta tendencia. Por lo demás, los anuncios de los médicos eran escuetos, pero a veces el reclamo incluía la referencia a alguna institución de prestigio. El Doctor Carrasco era Director del Hospital Civil y su cargo en la institución pública respaldaba su actividad privada. En sus anuncios, el doctor Salaverri se presentaba como "jefe de consulta de venéreos del Santo Hospital Civil", Antonio Rubio alegaba que era "profesor del Instituto Rubio", Juanita se anunciaba como "excomadrona de la Maternidad de Vizcaya"; De la Riva como "exjefe médico del Real Sanatorio de Guadarrama", el Dr. Bustamante era "exprofesor del Dispensario Antituberculoso Ledo" y Manuel de Echeverri Aldecoa era a su vez "médico del Manicomio de Zaldívar". En los anuncios, la modernidad quedó asociada a nuevos instrumentos médicos, como esfigmógrafos, microscopios y aparatos de Rayos $X$. También al uso de la electricidad y del ozono, a los que se conferían extraordinarias propiedades curativas. No estaba en Bilbao sino en Madrid, pero se anunciaba también el Instituto Radiumterápico de Madrid, para "enfermedades cancerosas", "infiltrando los rayos X y el Radium y obrando con ellos como si fuera un bisturí inteligente".

El cotejo de la publicidad médica en distintos diarios proporciona otro dato de gran interés. Durante el primer tercio del siglo se produjo una fragmentación social de la publicidad, al menos en los anuncios relacionados con la salud. La diferencia se produjo entre el periódico republicano-socialista El Liberal y los otros periódicos que, con sus diferencias doctrinales, se dirigían a las clases medias, frente al perfil más humilde de los lectores del primero. Las diferencias en los anuncios no se producen por tanto en virtud de la ideología sino de los grupos sociales a que se dirige el periódico.

Los anuncios médicos de Euskadi, La Gaceta del Norte y El Nervión son muy similares a los de El Noticiero Bilbaíno, sin sesgos específicos. El día elegido para el cotejo es el 30 de junio de 1921 (tabla 1). El Noticiero publicaba 14 anuncios de depurativos y específicos -Hemoglobina líquida, Píldoras Brandeth, Depurativo Fuster, elixires estomacales-, cuatro de belleza -Agua Argentina, Jabón Floralia, Loción Boyra, 8 de médicos y 1 con la Inyección Balamaseda para "Enfermedades secretas", entre otros productos menos significativos. El resto de periódicos "burgueses" presentaban un perfil muy similar. Euskadi, 10 depurativos y específicos -la marca norteamericana Sal de Frutas Eno para "purificar la sangre", Lactofitina, pastillas contra la tos y laxantes-, un par de artículos de belleza -destinados al cutis y cubrir las canas del cabello- y 5 médicos. En La Gaceta del Norte encontramos 3 anuncios de belleza -loción Boyra o Saltratos para los pies sensibles, que recurría a la artista Raquel Meller como reclamo publicitario, el reconstituyente Vino Bayard, 1 Jarabe antiepilético y 2 médicos. El Nervión era de menos anuncios: además de 4 médicos, 1 elixir estomacal, 1 de pastillas contra la tos, 1 laxante y el Elixir Callol, que "da fuerza, vigor y juventud".

La gama de anuncios y los argumentos empleados en sus textos y eslóganes eran similares en los cuatro periódicos, cuyos principales receptores eran las clases medias urbanas. El Liberal una gama bien distinta. No encontramos aquí artículos de belleza ni balnearios. Sí una docena de depurativos y específicos que no presentan grandes diferencias con los que solían aparecer en los otros diarios, incluyendo un ferruginoso

Revista de Comunicación y Salud, 2019, Vol. 9, n² 2, pp. 27-46 
presentado como "regenerador de la sangre" y los medicamentos del Dr. Soivré para las vías urinarias. Si acaso, puede notarse una definición más precisa de las enfermedades, con una gama más amplia: enfermedades de la piel, antisifilítico, laxantes y remedios contra las almorranas, embarazo gástrico, apoplejías, arterioesclerosis, hipertensión, tuberculosis, enfermedades de los ojos, hernias, bronquitis, tisis y sarna.

Pero la principal diferencia residía en el gran número de médicos que se anunciaban. Ese día lo hicieron 25, entre ellos 7 comadronas. Casi la mitad, 12, incluían en el anuncio alusiones a las enfermedades venéreas: "vías urinarias, secretas, piel", "inyecciones indoloras del 914, "Sífilis-venéreo-piel", "tratamiento de la sífilis por el neosalvarsan". Quizás las enfermedades venéreas habían estado peor controladas en los sectores humildes, a los que se dirigían los nuevos remedios basados en el salvarsán y en nuevas tecnologías, que exigían un control médico específico.

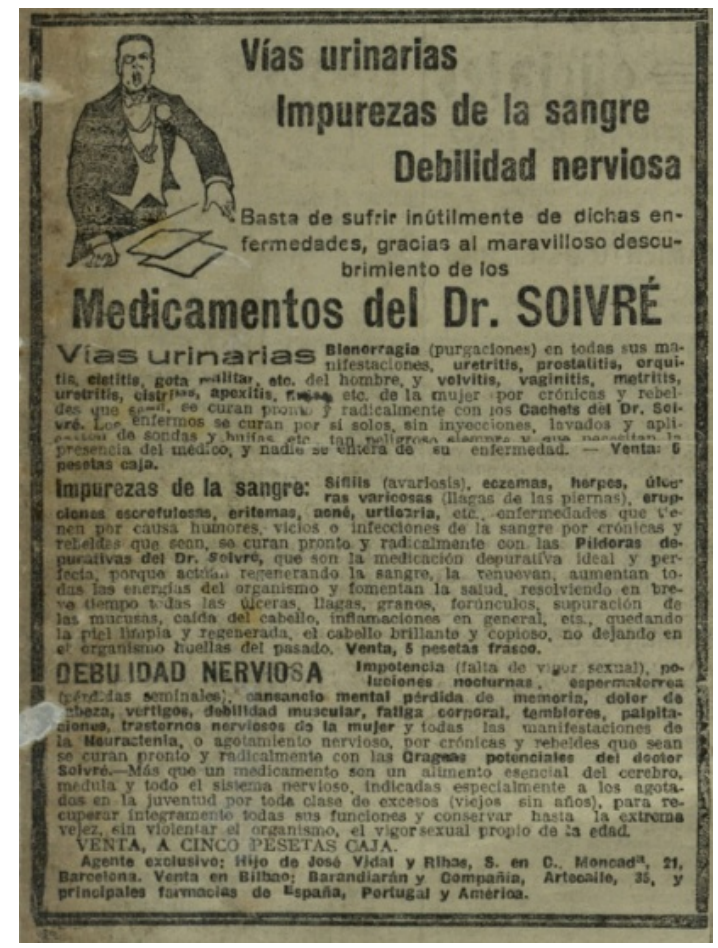

Figura 3. Anuncio Medicamentos del Dr. Soivré. Fuente: (1921, junio 30) El Liberal.

La atención a las enfermedades venéreas constituía, por tanto, el rasgo específico del periódico El Liberal y, junto a la ausencia de productos de belleza, permite hablar de cierta segmentación social de la publicidad, que concordaría con las distintas necesidades que generaba el cuidado de la salud. La diferenciación se produjo a partir de 1918, pues antes no encontramos en El Liberal un sesgo tan marcado. En 1916 su perfil era similar al de El Noticiero Bilbaíno: aguas de Vichy, balneario de La Muela, dos ópticas, pastillas contra la tos, quinina contra la gripe y varios médicos, de los que tres 
se dedicaban a enfermedades venéreas. En los 14 anuncios relacionados con la salud que publicaba en 1920 por las mismas fechas 7 eran ya médicos especializados en estas enfermedades, incluida una Clínica de Sifiloterapia, que ofrecía "tratamiento exclusivo de la sífilis por el Neo-Salvarsan Erlich, procedente de los depósitos del Estado alemán". Además, dos medicinas tenían alguna utilidad contra la sífilis y la blenorragia. Por tanto, la mayor parte de esta publicidad estaba relacionada con las venéreas. Había, además, dos anuncios de comadronas y uno para "la salud de las señoras". De este modo, el sesgo médico de El Liberal, proyección de la segmentación social, había quedado ya establecido.

\section{CONCLUSIONES}

En una visión de conjunto, hemos podido apreciar nítidos cambios en el botiquín doméstico reflejado en los anuncios, la modernización urbana desde el punto de vista del cuidado de la salud. Hemos constatado la disminución de la publicidad de productos médicos que se produjo durante los años veinte y, más aún, durante la siguiente década. Simultáneamente, aumentaron los anuncios de los profesionales médicos, así como de las clínicas y los gabinetes médicos. Todo indica por ello, que se redujo la automedicación.

Desde comienzos del siglo XX se produjo una reducción de la oferta de depurativos y reconstituyentes, que según los anuncios servían para enfermedades muy diferentes. Cambió por tanto la mentalidad, que progresivamente iba dejando de creer en las panaceas. Seguramente influyó una mayor precaución ante los efectos colaterales de estos productos, así como que se fueran desechando los que contenían estupefacientes. El éxito de los anuncios de gran formato de productos-milagro -de eficacia imposible- no podía deberse sólo a la eficacia del lema propagandístico. Anuncios caros y continuados, su mantenimiento tampoco se justificaría por sus presuntas funciones depurativas o reconstituyentes, no verificables a corto plazo. Su éxito tenía otra razón más inmediata: incluían opiáceos, coca u otras drogas. No conseguirían "purificar la sangre", pero sí provocar sensaciones que podían equiparase con una mejor salud.

Tales productos no solían publicar su composición, que solían declararse fórmulas secretas. Todavía a comienzos de siglo encontramos en los anuncios de algunos productos la afirmación de que contenían cocaína; y en algunos casos sabemos de la presencia de otras drogas. También en algunos otros se aseguraba: "no contiene opio ni opiáceos", "no provoca daños". Por tanto, no fue sólo la mentalidad. Hubo mayor conocimiento de los daños que podían producir tales productos y un nuevo Registro farmacéutico, que los limitó. Sí subsistió el argumento que hablaba de grandes efectos purificando la sangre. La confianza en la bondad definitiva de un único producto no llegó a desaparecer.

Caracteriza también a la maduración de las clases medias en el consumo médico la proliferación de específicos y nuevos tratamientos, que se presentaban como científicos o asociados a nuevas tecnologías, tales como electricidad, rayos $\mathrm{X}$, radioterapia $\mathrm{O}$

Revista de Comunicación y Salud, 2019, Vol. 9, n² 2, pp. 27-46 
nuevas técnicas antisifilíticas. Cabe citar, además, la presencia de productos relacionados con la belleza, presentada como una consecuencia de la higiene y con refrendo médico.

Finalmente, hemos constatado también la segmentación social de los anuncios médicos, visibles en la mayor presencia de remedios contra las enfermedades venéreas en la prensa dirigida a los grupos más humildes, en la que escaseaban los productos relacionados con la belleza mientras que se ofertaban específicos contra una amplísima gama de enfermedades. Hemos mostrado, en definitiva, la relación entre cambios sociales y cambios comunicativos en el marco del crecimiento urbano en la España del primer tercio del siglo XX, a través del análisis de los anuncios publicitarios del sector de la medicina y la farmacopea. Igualmente, el trabajo contribuye a un mejor entendimiento de las transformaciones de los usos y costumbres en la sociedad urbana española del periodo.

\section{REFERENCIAS}

Balandrón Pazos, A. J., Correyero-Ruiz, B. y Villalobos Montes, $M^{a}$. M. (2007). Mujer y publicidad en los felices años veinte: un análisis de contenido de la revista ilustrada Blanco y Negro. Comunicación y pluralismo, 3, 117-139.

Barker, H. (2009). Medical advertising and trust in late Georgian England. Urban History, 36, 379-398. doi: https://doi.org/10.1017/S0963926809990113

Bermejo Berros, J. (Coord.) (2005). Publicidad y cambio social. Contribuciones históricas y perspectivas de futuro. Sevilla: Comunicación Social Ediciones y Publicaciones.

De Andrés del Campo, S. (2005). Estereotipos de género en la publicidad de la Segunda República Española. Granada: Universidad de Granada.

De Bruc, C. (1873). Formulario médico de las familias. Valencia: Librería de Juan Mariana y Sanz, Editor.

Eguizábal, R. (2009). Industrias de la conciencia: una historia social de la publicidad en España (1975-2009). Barcelona: Península.

Fernández Poyatos, $M^{a}$. D. (2011). La publicidad de salud en la prensa ilustrada de finales del siglo XIX. Questiones Publicitarias, 16, 108-124.

Fresquet Febrer, J. L. (2011). La introducción del '606' en España contada por la prensa diaria. El Argonauta español, http://journals.openedition.org/argonauta/122

González Bueno, A. et al. (1995). La industria farmacéutica en España (1919-1933): una visión desde el Registro de especialidades farmacéuticas. En Aceves Pastrana, P. (Ed.), Las ciencias químicas y biológicas en la formación del Nuevo Mundo. 
Cambios sociales y comunicativos a través de la publicidad médica y farmacéutica en la prensa histórica de Bilbao, 1885-1936

Estudios de historia social de las ciencias químicas y biológicas, 2 (pp. 373-383). México.

González Mesa, I. M. (2010). El espejo mágico: la sociedad española de la III República según la publicidad de la revista Crónica (1931-1936). Revista Mediterránea de Comunicación, 1, 195-212.

Marchamalo, J. (1996). Bocadillos de delfín. Anuncios y vida cotidiana en la España de la postguerra. Madrid: Grigalbo.

Montero Díaz, M. (2011). Mujer, publicidad y consumo en España. Una aproximación diacrónica. Anagramas, 18, 83-92.

Rodríguez Martín, N. (2007): (2008). Jóvenes, modernas y deportistas: la construcción de nuevos roles sociales en la España del primer tercio del siglo XX a través de la publicidad. En Nicolás, E. y González, C. (Eds.), Ayeres en discusión. Temas claves de Historia Contemporánea hoy. Murcia: Editum.

Rodríguez Martín, N. (2015). Cuando Carmen va de compras. Clases medias y sociedad de consumo en el Madrid del primer tercio del siglo XX. En Beascoechea Gangoiti, J. Ma. y Otero Carvajal, L. E. (Eds.), Las nuevas clases medias urbanas. Transformación y cambio social en España, 1900-1936, (pp. 170-185). Madrid: Catarata.

Sáiz Valdivielso, A. C. (2000). Bilbao, periódicos y periodistas. Bilbao: Fundación Bilbao 700.

Seoane, $M^{a}$ C. y Saiz, $M^{a}$ D. (1996). Historia del periodismo en España. 3. El siglo XX: 1898-1936. Madrid: Alianza.

Suñé Arbussa, J. M. y Valverde López, J. L. (1985). Del remedio secreto a la especialidad farmacéutica: evolución legal en España. En Puerto Sarmiento, F.J. Farmacia e industrialización. Homenaje al Doctor Guillermo Folch Jou (pp. 83-93). Madrid: Editorial Española de Historia de la Farmacia.

Urquijo Goitia, M. (2005). De la prensa evangelizadora al Factory System de la comunicación (Bilbao, 1868-1937). Bidebarrieta, 16, 111-140.

VV.AA. (1992). Una historia de la publicidad en España: Reflejos de más de un siglo de Nestlé. Barcelona, Sociedad Nestlé.

VV.AA. (2013). Bebés. Usos y costumbre sobre el nacimiento. Catálogo de la exposición temporal. Madrid: Ministerio de Educación, Cultura y Deporte. 
Cambios sociales y comunicativos a través de la publicidad médica y farmacéutica en la prensa histórica de Bilbao, 1885-1936

\section{AUTORES}

\section{Manuel Montero}

Catedrático de Historia Contemporánea y ex Rector de la Universidad del País Vasco. Es director del Grupo de Investigación Demografía Histórica e Historia Urbana. Es autor, entre otros, de El sueño de la libertad. Mosaico vasco de los años del terror, Oviedo, Ediciones Nobel, 2018 (XXIV Premio Internacional de Ensayo Jovellanos de Ensayo).

Orcid ID: https://orcid.org/0000-0002-1905-9323

\section{Nuria Rodríguez-Martín}

Doctora Contratada en la Universidad de Málaga. Es Licenciada en Ciencias de la Información y Doctora en Historia por la UCM. Ha sido Lectora de español en la Universidad Paris-Sorbonne e Investigadora Juan de la Cierva en la Universidad del País Vasco.

Orcid ID: https://orcid.org/0000-0003-0179-7392

Academia.edu: https://uma.academia.edu/NuriaRodr\%C3\%ADguezMart\%C3\%ADn 